DIMENSI, VOL. 8 , NO. $3: 432-448$

NOVEMBER 2019

ISSN: 2085-9996

\title{
ANALISIS FUNGSI PENGAWASAN UJI BERKALA OLEH DINAS PERHUBUNGAN KOTA BATAM TERHADAP ANGKUTAN KOTA
}

\section{ANALYSIS FUNCTION CONTROL OF PERIODIC TEST BY THE DEPARTMENT OF TRANSPORTATION TOWARD CITY TRANSPORTATION}

\author{
Kiki Yunita Sari ${ }^{1}$, Linayati Lestari ${ }^{2}$, Nurhayati $^{3}$ \\ I(Prodi Ilmu Pemerintahan, Fakultas Ilmu Sosial \& Ilmu Politik, Universitas Riau Kepulauan, Indonesia) \\ ${ }^{2}$ (Prodi Ilmu Pemerintahan, Fakultas Ilmu Sosial \& Ilmu Politik, Universitas Riau Kepulauan, Indonesia) \\ ${ }^{3}$ (Prodi Ilmu Pemerintahan, Fakultas Ilmu Sosial \& Ilmu Politik, Universitas Riau Kepulauan, Indonesia) \\ ${ }^{1}$ kikiyunita@gmail.com, ${ }^{2}$ linayatilestari@yahoo.com ${ }^{3,}$ nurhayati@fisip.unrika.ac.id
}

\begin{abstract}
Abstrak
Dalam rangka penertiban angkutan umum, sebagaimana tertuang dalam Undang-Undang Nomor 22 Tahun 2009 Pasal 5 ayat 2 tentang Lalu Lintas dan Angkutan Jalan menjelaskan bahwa "Pembinaan Lalu Lintas dan Angkutan Jalan sebagaimana dimaksud pada ayat (1) meliputi perencanaan, pengaturan, pengendalian dan pengawasan. Untuk menjamin kelayakan kendaraan penumpang atau barang (angkot, bus, truk) yang ada di jalan sudah seharusnya diawasi oleh Pemerintah. Berdasarkan permasalahan yang diuraikan maka rumusan masalah penelitian adalah bagaimana Analisis Fungsi Pengawasan Uji Berkala Oleh Dinas Perhubungan Terhadap Angkutan Kota di Kota Batam. Penelitian ini bertujuan untuk mengetahui pelaksanaan penertiban angkutan umum di Kota Batam oleh Pemerintah khususnya Dinas Perhubungan serta mengetahui kesesuaian pelaksanaan penertiban angkutan umum di Kota Batam oleh Dinas Perhubungan sesuai dengan Peraturan Daerah Kota Batam Nomor 9 Tahun 2001 Tentang Lalu Lintas dan Angkutan Jalan Pasal 42 ayat 1. Penelitian ini merupakan penelitian Kualitatif. Lokasi penelitian di Kantor Dinas Perhubungan. Pengumpulan data dilakukan melalui observasi, wawancara, dan dokumentasi. Hasil penelitian ini menunjukkan bahwa dalam menangani penertiban angkutan umum di Kota Batam sudah sesuai dengan aturan dan perundang-undangan yang berlaku, namun masih perlu membenahi terhadap kelemahan-kelemahan yang ada. Dalam hal penertiban angkutan umum yang masih banyak tersebar di Kota Batam, disarankan agar pemerintah dalam hal ini bertindak tegas sesuai dengan prosedur yang berlaku serta lebih mengedepankan sikap ramah, dan bersahabat terhadap supir angkutan umum, agar tidak terjadi kesalahpahaman antara supir angkutan umum dan pihak-pihak dari Dinas Perhubungan.
\end{abstract}

Kata Kunci; Analisis, Pengawasan, Uji Berkala KIR, Penertiban, Angkutan Kota.

\begin{abstract}
In the context of controlling public transportation, as stipulated in Law Number 22 Year 2009 Article 5 paragraph 2 concerning Road Traffic and Transportation explains that "Road Traffic and Transport Development as referred to in paragraph (1) includes planning, regulation, control and supervision. To ensure the feasibility of passenger vehicles or goods (public transportation, buses, trucks) that are on the road should be monitored by the Government.
\end{abstract}


DIMENSI, VOL. 8 , NO. $3: 432-448$

NOVEMBER 2019

ISSN: 2085-9996

Based on the problems outlined, the formulation of the research problem is how the Analysis of the Periodic Test Oversight Function By the Department of Transportation Against City Transportation in Batam City. This study aims to determine the implementation of public transportation control in Batam City by the Government, especially the Transportation Department and determine the suitability of the implementation of public transportation control in Batam City by the Transportation Department in accordance with Batam City Regional Regulation No. 9 of 2001 Concerning Traffic and Road Transportation Article 42 paragraph 1. This research is a qualitative research. Research location in the Office of Transportation. Data collection is done through observation, interviews, and documentation. The results of this study indicate that in dealing with control of public transportation in Batam City is in accordance with the applicable rules and legislation, but it still needs to be addressed to the existing weaknesses. In terms of controlling public transportation which is still widely spread in Batam City, it is recommended that the government in this case act decisively in accordance with applicable procedures and prioritize a friendly, friendly attitude towards public transportation drivers, so that misunderstandings between public transport drivers and parties party from the Department of Transportation.

Keywords; Analysis, Supervision, Periodic Test of KIR, Ordering, City Transportation.

\section{PENDAHULUAN}

Dalam Undang-Undang Nomor 22 Tahun 2009 Pasal 5 ayat 2 tentang Lalu Lintas dan Angkutan Jalan menjelaskan bahwa "Pembinaan Lalu Lintas dan Angkutan Jalan sebagaimana dimaksud pada ayat (1) meliputi perencanaan, pengaturan, pengendalian dan pengawasan. Untuk menjamin kelayakan kendaraan penumpang atau barang (angkot, bus, truk) yang ada di jalan sudah seharusnya diawasi oleh Pemerintah.Pengawasan yang dilakukan tersebut berupa uji KIR (uji berkala). Uji berkala yang dilakukan pemerintah khususnya Kementerian Perhubungan sudah jelas diatur dalam Undang-Undang Nomor 22 tahun 2009 tentang Lalu Lintas dan Angkutan Jalan (PP LLAJ) serta diperdalam pembahasannya pada Peraturan Menteri Perhubungan Republik Indonesia Nomor PM 133 tahun 2015 tentang Pengujian Berkala Kendaraan Bermotor (Permenhub PBKB).

Pada pasal 53 ayat satu UU LLAJ, uji berkala sebagaimana dimaksud, wajib dilakukan untuk mobil penumpang umum, bus, barang, kereta gandengan, dan kereta tempelan yang dioperasikan di Jalan. Lalu pada pasal 2, pengujian berkala tersebut meliputi kegiatan, pemeriksaan dan pengujian fisik, serta pengesahan hasil uji. Selain pada pasal 53, aturan uji berkala ini secara lebih lanjut diperjelas pada pasal 54 dan 55 UU LLAJ. Terkait dengan waktu pelaksanaanya juga sudah dijelaskan pada pasal 5 ayat 
3 Permenhub PBKB, di mana uji berkala perdana dilakukan paling lama satu tahun setelah terbit surat tanda nomor kendaraan (STNK) yang pertama kali. Kemudian pada ayat 3, perpanjangan uji berkala selanjutnya dilakukan enam bulan setelah uji berkala pertama, dan dilakukan terus menerus setiap enam bulan sekali.

Berdasarkan Undang-Undang Nomor 22 Tahun 2009 Pasal 3 tentang Lalu Lintas dan Angkutan Jalan diselenggarakan dengan tujuan :

1. Terwujudnya pelayanan Lalu Lintas dan Angkutan Jalan yang aman, selamat, tertib, lancar, dan terpadu dengan moda angkutan lain untuk mendorong perekonomian nasional, memajukan kesejahteraan umum, memperkukuh persatuan dan kesatuan bangsa, serta mampu menjunjung tinggi martabat bangsa.

2. Terwujudnya etika berlalu lintas dan budaya bangsa, dan

3. Terwujudnya penegakan hukum dan kepastian hukum bagi masyarakat.

Batam sebagai salah satu Kota besar di Indonesia mempunyai arus lalu lintas dan mobilitas masyarakat yang tinggi. Pengembangan dan pembangunan Kota Batam salah satunya terwujud dengan adanya pemusatan dan penyebaran lokasi kegiatan masyarakat seperti pasar, perumahan, perkantoran, rumah sakit maupun sekolah.Aktifitas masyarakat pada lokasi-lokasi tersebut perlu ditunjang dengan adanya sarana transportasi berupa angkutan umum yang memadai dapat kita lihat pembangunan Daerah Kota Batam berkembang cukup pesat. Pertumbuhan penduduk dan meningkatnya kebutuhan ekonomi menjadi salah satu pemicu lajunya arus urbanisasi di Kota Batam yang secara tidak langsung berdampak pada meningkatnya kebutuhan akan jasa transportasi.

Dengan jumlah kendaraan yang meningkat setiap tahunnya membuat masyarakat Batam harus lebih sabar dalam menghadapi macet yang biasa terjadi pada pukul 08.00 WIB saat pergi kerja dan pukul 16.00-19.00 WIB saat pulang kerja. Kemacetan pun dapat dilihat seperti gambar dibawah ini : 
Gambar 1: Suasana Kemacetan di Lampu Merah Muka Kuning

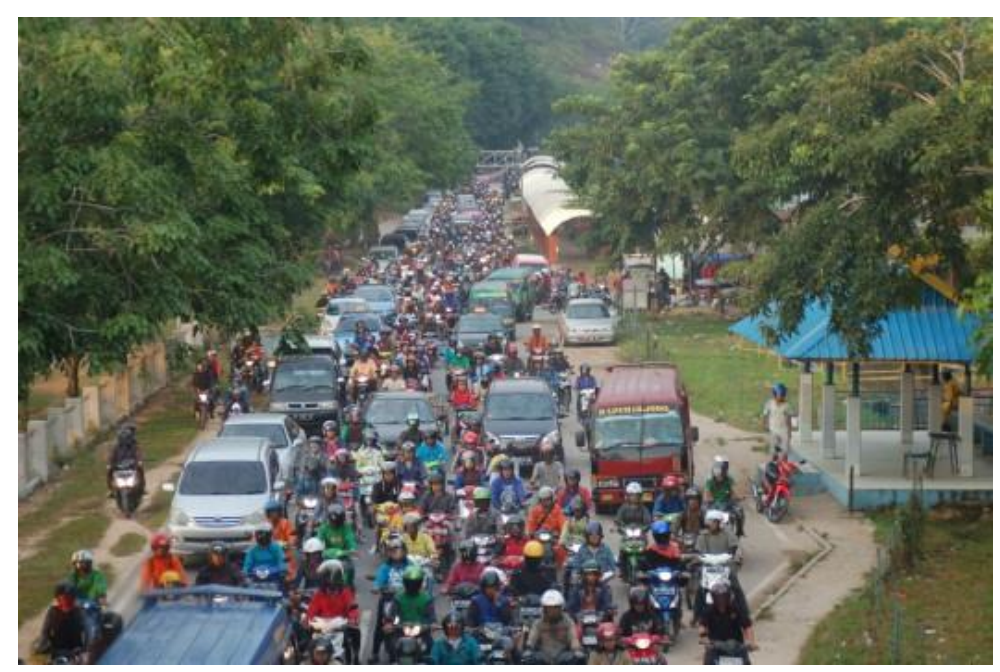

Sumber : www.posmetro.co.id, Tahun 2017

Saat macet terjadi, dapat kita lihat berbagai jenis kendaraan dari kendaraan roda dua, roda empat dan angkutan umum. Angkutan umum perkotaan adalah salah satu tulang punggung ekonomi perkotaan dimana kota yang "baik" dan "sehat" dapat ditandai dengan melihat kondisi sistem angkutan umum apakah angkutan umum tersebut laik atau tidak untuk beroperasi. Namun kenyataan yang kita lihat masih ada angkutan umum yang sudah tidak laik beroperasi tetapi masih mengangkut penumpang, dan bahkan ada yang melebihi kapasitas. Adapun titik-titik lokasi yang sering mengalami kemacetan, seperti tabel di bawah ini:

Tabel 1: Lokasi Terjadi Kemacetan di Kota Batam

\begin{tabular}{|c|l|l|}
\hline NO & LOKASI MACET & WAKTU MACET \\
\hline 1 & Simpang Kabil & Pagi (07.00-08.00 WIB), sore (16.00-19.00 WIB) \\
\hline 2 & Simpang Jam & Pagi (07.00-08.00 WIB), sore (16.00-19.00 WIB) \\
\hline 3 & Simpang Gelael & Pagi (07.00-08.00 WIB), sore (16.00-19.00 WIB) \\
\hline 4 & Simpang Panbil & Pagi (07.00-08.00 WIB), sore (16.00-19.00 WIB) \\
\hline 5 & Simpang Lampu Barelang & Pagi (07.00-08.00 WIB), sore (16.00-19.00 WIB) \\
\hline 6 & Nagoya & Pagi (07.00-08.00 WIB), sore (16.00-19.00 WIB) \\
\hline
\end{tabular}

Kota Batam tidak terlepas dari masalah angkutan umum yang sering terjadi yaitu kondisi kendaraan yang sudah tidak laik, surat perizinan mobil yang tidak lengkap seperti 
BPKB dan STNK, adapun masalah dengan supir angkutan umum yang tidak mempunyai SIM. Sesuai dengan Peraturan Daerah Kota Batam Nomor 9 Tahun 2001 tentang Lalu Lintas dan Angkutan Jalan Pasal 42 ayat 1 dijelaskan "Setiap kendaraan bermotor sebelum dioperasikan dijalan wajib didaftarkan untuk mendapat Buku Pemilikan Bermotor (BPKB), Surat Tanda Nomor Kendaraan Bermotor (STNK) dan tanggal nomor kendaraan (Plat Nomor).

Dalam kehidupan sehari-hari bidang kegiatan transportasi atau pengangkutan sangat penting dan tidak dapat dipisahkan dari aktifitas kehidupan masyarakat Indonesia.Mulai dari zaman kehidupan manusia yang paling sederhana (tradisional) sampai kepada taraf kehidupan manusia yang modern selalu didukung oleh kegiatan pengangkutan. Pentingnya transportasi bagi masyarakat Indonesia dilihat dari beberapa faktor antara lain, keadaan geografis Indonesia yang terdiri dari ribuan pulau, perairan yang terdiri dari sebagian besar laut, sungai dan danau yang bisa memungkinkan pengangkutan dilakukan melalui jalur darat, perairan, dan udara guna menjangkau seluruh wilayah Indonesia.

Pentingnya pengangkutan ditunjukan untuk membantu orang dan/atau barang berpindah dari satu tempat ke tempat lain. Pengangkutan itu merupakan perpindahan tempat, baik mengenai benda-benda maupun orang-orang. ${ }^{1} \mathrm{Hal}$ lain yang juga tidak kalah pentingnya akan kebutuhan alat transportasi adalah kebutuhan kenyamanan, keamanan, dan kelancaran pengangkutan yang menunjang pelaksanaan pengiriman barang, perdagangan, pariwisata maupun pendidikan.Angkutan Kota sangat bermanfaat sebagai sarana transportasi perkotaan, tetapi selain pihak keberadaan angkutan umum sering kali mengundang bahaya dan ketidak tertiban akibat sifat tidak disiplin dari pengemudi angkutan umum. Sikap pengemudi angkutan umum seringkali tidak mematuhi tata tertib lalu lintas, misalnya seperti menaikkan penumpang di sembarang tempat, di daaerahdaerah pasar tradisional, sekolah atau pusat perbelanjaan dengan menaiki penumpang yang berlebihan, berebut penumpang, kebut-kebutan dan berhenti secara mendadak dan tidak ada tempat semestinya. Hal ini menyebabkan ketidaknyamanan masyarakat sekitar dalam pelaksanaan kegiatan mereka sehari-hari seperti menyebabkan kemacetan dan

\footnotetext{
${ }^{1}$ Sution Usman Adji, 1991, Hukum Pengangkutan di Indonesia, Rineka Cipta, Jakarta: hal.1.
} 
rawan akan kecelakaan pengemudi angkutan umum yang tidak mematuhi tata tertib lalu lintas.

\section{Gambar 2: Kerangka Pemikiran}

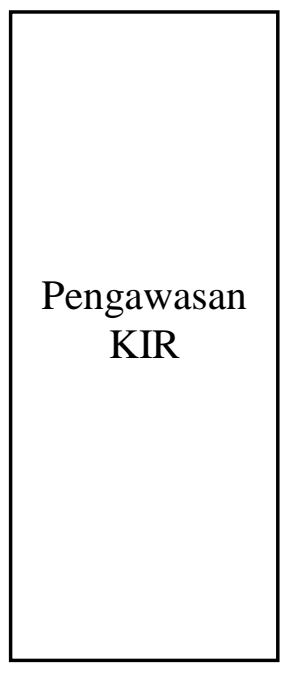

Langsung :

- Pengujian Berkala Kendaraan Bermotor

- Pemeriksaan dan Pengujian Fisik

$\rightarrow$ Pengesahan Hasil Uji

Tidak Langsung

- Dokumen

- Surat Pengaduan

- Berita atau artikel di media massa

Berdasarkan skema kerangka pikir diatas, dapat diketahui bahwa kerangka pikir yang digunakan peneliti sangat berpengaruh pada upaya Dinas Perhubungan dalam pengawasan penertiban angkutan umum.

\section{METODOLOGI}

\section{Jenis Penelitian}

Jenis penelitian menggunakan kualitatif deskriptif yaitu untuk mengetahui dan menggambarkan fungsi pengawasan Dinas Perhubungan dalam penertiban angkutan umum di Kota Batam.Menurut Bogdan dan Taylor (1992) menjelaskan bahwa penelitian kualitatif adalah salah satu prosedur penelitian yang meghasilkan data deskriptif berupa ucapan atau tulisan dan perilaku orang-orang yang diamati. Pendekatan kualitatif diharapkan mampu menghasilkan uraian yang mendalam tentang ucapan, tulisan, dan atau perilaku yang dapat di amati dari suatu individu, kelompok, masyarakat dan atau organisasi tertentu dalam suatu keadaan konteks tertentu yang dikaji dari sudut pandang yang utuh, kompherensif, dan holistic. 


\section{Populasi dan Sampel}

Populasi adalah himpunan individu atau objek yang banyaknya terbatas dan tidak terbatas. Himpunan individu atau objek yang terbatas adalah himpunan objek yang dapat diketahui atau diukur dengan jelas jumlah maupun batasnya. Sedangkan himpunan individu atau objek yang tidak terbatas merupakan himpunan individu atau objek yang sulit diketahui jumlahnya walaupun batas wilayahnya sudah diketahui. Pada penelitian ini populasinya adalah semua pegawai Dinas Perhubungan Kota Batam. Sampel yang di ambil dalam penelitian ini berjumlah 13 orang yang merupakan pegawai Kantor Dinas Perhubungan Kota Batam 4 orang, supir angkutan umum 5 orang dan masyarakat 4 orang.

\section{PEMBAHASAN}

Tabel 2: Jenis-Jenis Angkutan umum yang ada di Kota Batam

\begin{tabular}{|c|c|c|c|}
\hline No & $\begin{array}{c}\text { Jenis Angkutan } \\
\text { Umum }\end{array}$ & $\begin{array}{l}\text { Warna/ } \\
\text { Koridor }\end{array}$ & Trayek \\
\hline \multirow{7}{*}{1.} & \multirow{7}{*}{ Angkot } & Putih/Merah Muda & Jodoh-Nongsa \\
\hline & & Coklat & Muka Kuning-Batu Aji \\
\hline & & Hijau & Jodoh-Bengkong \\
\hline & & Kuning & Bengkong-Muka Kuning \\
\hline & & Oranye & Jodoh-Punggur \\
\hline & & Merah Tua & Jodoh-Batu Aji-Dapur 12 via Sukajadi \\
\hline & & Biru Tua & $\begin{array}{l}\text { Jodoh-Batu Aji-Tangjung Uncang via } \\
\text { Batam Center }\end{array}$ \\
\hline \multirow{9}{*}{2.} & \multirow{9}{*}{ Bus Trans Batam } & 01 & Sekupang-Batam Center \\
\hline & & 02 & Tg.Uncang-Batam Center \\
\hline & & 03 & Sekupang-Jodoh \\
\hline & & 04 & Tg.Uncang-Sekupang \\
\hline & & 05 & Tg.Piayu-Jodoh \\
\hline & & 06 & Nongsa-Batam Center \\
\hline & & 07 & Punggur-Jodoh \\
\hline & & 08 & Nongsa-Punggur \\
\hline & & 09 & Tembesi-Galang \\
\hline \multirow[t]{2}{*}{3} & \multirow[t]{2}{*}{ Taksi } & Black Horse & \multirow{2}{*}{ Seluruh Kota Batam } \\
\hline & & Blue Bird & \\
\hline
\end{tabular}

Sumber: www.jotravelguide.co.id 
Dari data diatas bahwa banyak terdapat 3 jenis angkutan umum yang ada di Kota Batam. Angkot memiliki 7 warna dengan trayek yang berbeda, bus trans Batam memiliki 8 koridor dengan masing-masing trayek yang sudah di tentukan. Sedangkan taksi boleh beroperasi di seluruh Kota Batam. Hal ini dikarenakan tidak ada kesepakatan pembagian wilayah pengangukutan antar jenis-jenis taksi.

Yang menjadi konsep pengawasan dari penelitian ini adalah pengawasan uji KIR menurut S.P. Siagian meliputi: pengawasan langsung dan tidak langsung. Dimana pengawasan langsung yaitu : Pengujian Berkala Kendaraan Bermotor, Pemeriksaan dan Pengujian Fisik, dan Pengesahan Hasil Uji. Sedangkan pengawasan tidak langsung yaitu : dokumen, pengaduan dan artikel atau media masa yang akan diuraikan sebagai berikut:

\section{Pengawasan Langsung}

Pengawasan langsung yaitu pengawasan yang dilakukan berdasarkan hasil wawancara dengan narasumber yang terkait. Hal-hal yang meliputi pengawasan langsung yaitu:

1. Pengujian Berkala Kendaraan Bermotor dalam standar dan tujuan pengujian KIR

Kendaraan bermotor angkutan umum wajib dilakukan Pengujian berkala sesuai dengan Peraturan Menteri Perhubungan Republik Indonesia Nomor PM 133 Tahun 2015 tentang Pengujian Berkala Kendaraan Bermotor menyebutkan bahwa uji berkala KIR kendaraan bermotor yang dilakukan terhadap setiap kendaraan bermotor di jalan khususnya angkutan umum sangat penting karena dengan pengujian berkaitan hubungannya dengan perizinan.

Dalam merumuskan standar dan tujuan pengujian KIRmaka terlebih dahulu harus melakukan analisis yaitu apa yang akan dicapai melalui pengawasan serta pertimbangan-pertimbangan terhadap sejumlah alternatif yang berbeda baik yang berwujud maupun tidak, jangka pendek, menengah atau panjang dan harusjelasdan terukur sehingga dapat direalisir. 
Gambar 3: Standar Operasional Pengujian Berkala Kendaraan Bermotor

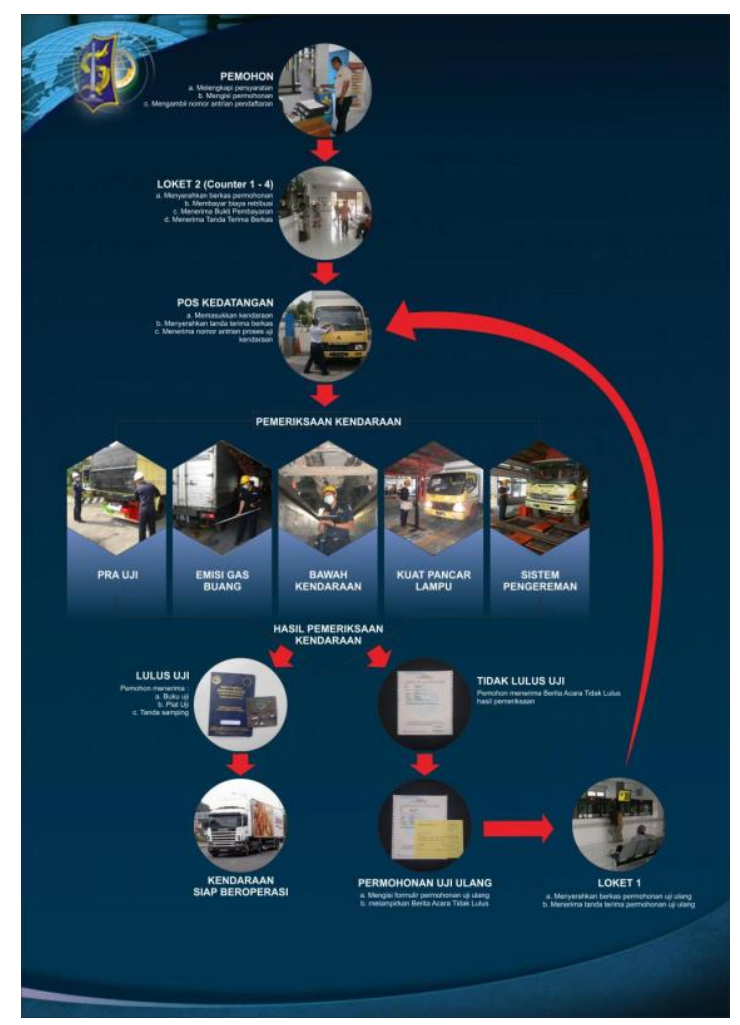

Sumber: Dinas Perhubungan Kota Batam

2. Pemeriksaan dan Ujian Fisik

Pemeriksaan dan uji fisik merupakan salah satu faktor penting dalam proses pengawasan uji berkala KIR, dimana tanpa adanya pemeriksaan dan ujian fisik, maka besar kemungkinan banyak angkutan umum yang tidak laik beroperasi namun banyak dijumpai di jalanan Kota Batam.

Gambar 4: Kondisi Angkutan Umum yang sudah tidak layak Beroperasi

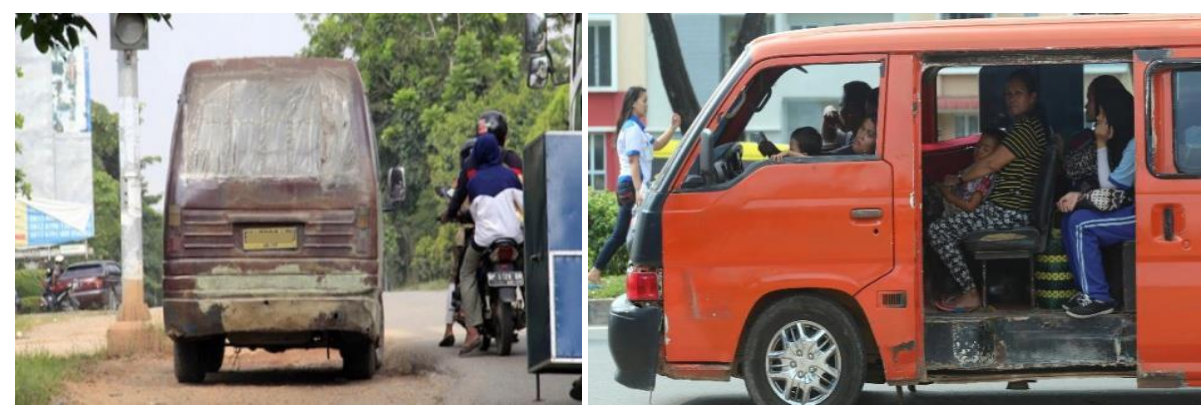

Sumber: Dinas Perhubungan Kota Batam 


\section{Pengesahan Hasil Uji}

Setelah dilakukan pemeriksaan dan hasil uji fisik terhadap angkutan umum ataupun barang, tahap terakhir yaitu pengesahan hasil uji. Dimana sebelumnya harus melalui beberapa proses sampai akhirnya menerima pengesahan hasil uji yang diberikan oleh Dinas Perhubungan kepada badan usaha angkutan yang sudah melakukan uji berkala KIR. Uji berkala KIR sendiri dilakukan minimal 6 bulan sekali.

\section{Gambar 5: Stiker Uji Berkala KIR}

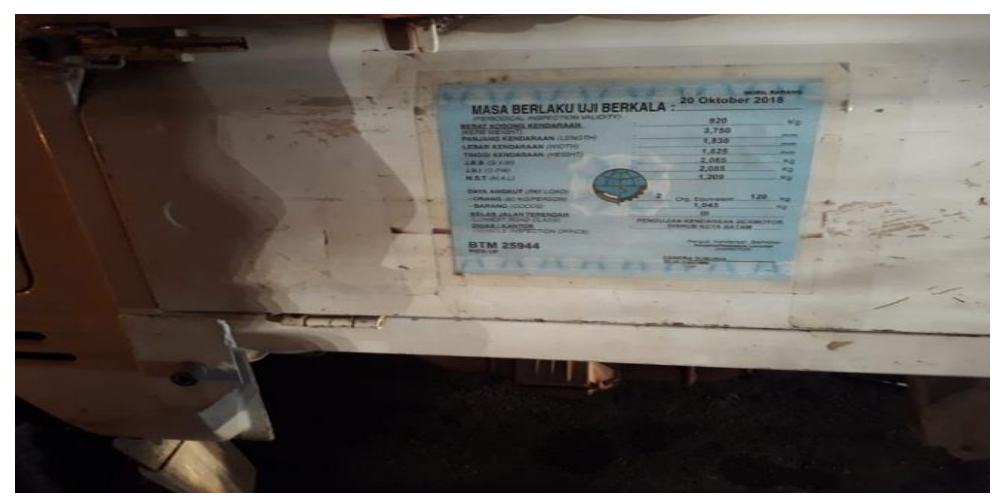

Sumber: Dinas Perhubungan Kota Batam

Di dalam pelaksanaan pemeriksaan dan ujian fisik sudah dilakukan sesuai prosedur, namun tidak dapat dipungkiri bahwa masih ada kecurangan dari oknum-oknum yang tidak bertanggung jawab yang sudah memalsukan buku KIR

\section{Pengawasan Tidak Langsung}

Pengawasan tidak langsung yaitu pengawasan yang dilakukan berdasarkan hal-hal berikut:

1. Dokumen

Dokumen merupakan surat berharga yang ditulis atau dicetak yang digunakan sebagai keterangan atau bukti secara nyata. Dokumen merupakan bagian penting dari pengawasan tidak langsung. Pengawasan KIR dapat di nilai terlaksana dengan baik atau tidak dapat dilihat melalui hasil pengawasan di lapangan yang dibuat dalam sebuah catatan atau dokumen.Seperti dokumen dibawah ini: 
Tabel 3: Angkutan Orang Dengan Kendaraan Umum 2014-2016

\begin{tabular}{|c|c|c|c|c|}
\hline \multirow{2}{*}{ No } & \multirow{2}{*}{ Jenis Angkutan } & \multicolumn{3}{|c|}{ Tahun } \\
\hline & & 2014 & 2015 & 2016 \\
\hline \multirow[t]{4}{*}{1} & Taksi & & & \\
\hline & $\begin{array}{l}\text { Layak Usia Operasi } \\
\text { (usia kendaraan maksimal dari } 15 \text { tahun) }\end{array}$ & 1450 & 1431 & 1320 \\
\hline & $\begin{array}{l}\text { Habis Usia Operasi } \\
\text { (usia kendaraan lebih dari } 15 \text { tahun) }\end{array}$ & 1134 & 1362 & 1489 \\
\hline & JUMLAH & 2584 & 2773 & 2809 \\
\hline \multirow[t]{3}{*}{2} & $\begin{array}{l}\text { Trayek Utama } \\
\text { Layak Usia Operasi } \\
\text { (usia kendaraan maksimal dari } 18 \text { tahun) }\end{array}$ & 373 & 312 & 274 \\
\hline & $\begin{array}{l}\text { Habis Usia Operasi } \\
\text { (usia kendaraan lebih dari } 18 \text { tahun) }\end{array}$ & 244 & 320 & 452 \\
\hline & JUMLAH & 617 & 632 & 726 \\
\hline \multirow[t]{3}{*}{3} & $\begin{array}{l}\text { Trayek Cabang } \\
\text { Layak Usia Operasi } \\
\text { (usia kendaraan maksimal dari } 15 \text { tahun) }\end{array}$ & 841 & 483 & 402 \\
\hline & $\begin{array}{l}\text { Habis Usia Operasi } \\
\text { (usia kendaraan lebih dari } 15 \text { tahun) }\end{array}$ & 904 & 1290 & 1321 \\
\hline & JUMLAH & 1745 & 1773 & 1723 \\
\hline \multirow[t]{3}{*}{4} & $\begin{array}{l}\text { Trayek Ranting } \\
\text { Layak Usia Operasi } \\
\text { (usia kendaraan maksimal dari } 15 \text { tahun) }\end{array}$ & 0 & 0 & 0 \\
\hline & $\begin{array}{l}\text { Habis Usia Operasi } \\
\text { (usia kendaraan lebih dari } 15 \text { tahun) }\end{array}$ & 101 & 101 & 101 \\
\hline & JUMLAH & 101 & 125 & 143 \\
\hline 5 & Angkutan Karyawan & 191 & 265 & 398 \\
\hline 6 & Angkutan Pariwisata & 42 & 67 & 82 \\
\hline
\end{tabular}

Sumber: Data dari Dinas Perhubungan Kota Batam

Berdasarkan tabel 3.4 tentang data angkutan orang dengan kendaraan umum tahun 2014-2016 jenis angkutan taksi, trayek utama, trayek cabang, trayek ranting yang layak usia operasi (usia kendaraan maksimal dari 15 tahun) dari tahun 20142016 mengalami penurunan. Sedangkan jenis angkutan taksi, trayek utama, trayek cabang, trayek ranting yang habis usia operasi (usia kendaraan lebih dari 15 tahun) dari tahun 2014-2016 mengalami peningkatan. Taksi berjumlah 2547 kendaraan, 
trayek utama berjumlah 617 kendaraan, trayek cabang berjumlah 1745 kendaraan, trayek ranting berjumlah 101 kendaraan, angkutan karyawan berjumlah 191 kendaraan sedangkan angkutan pariwisata mengalami peningkatan setiap tahunnya.

Gambar 5: Dokumen Pelaksanaan uji KIR

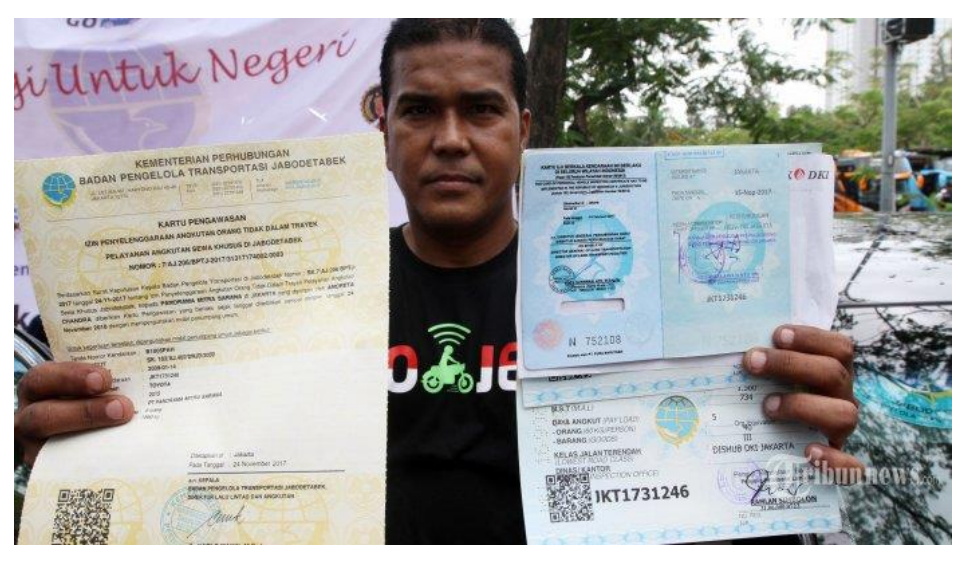

2. Pengaduan

www.tribunnews.com

Pengaduan adalah pemberitahuan yang disertai permintaan oleh pihak yang berkepentingan kepada instansi khususnya Dinas Perhubungan yang berwenang untuk menindak menurut ketentuan, terhadap seseorang atau badan usaha angkutan kota yang tidak sesuai aturan yang berlaku.

Gambar 6: Tata Cara Layanan Pengaduan Masyarakat

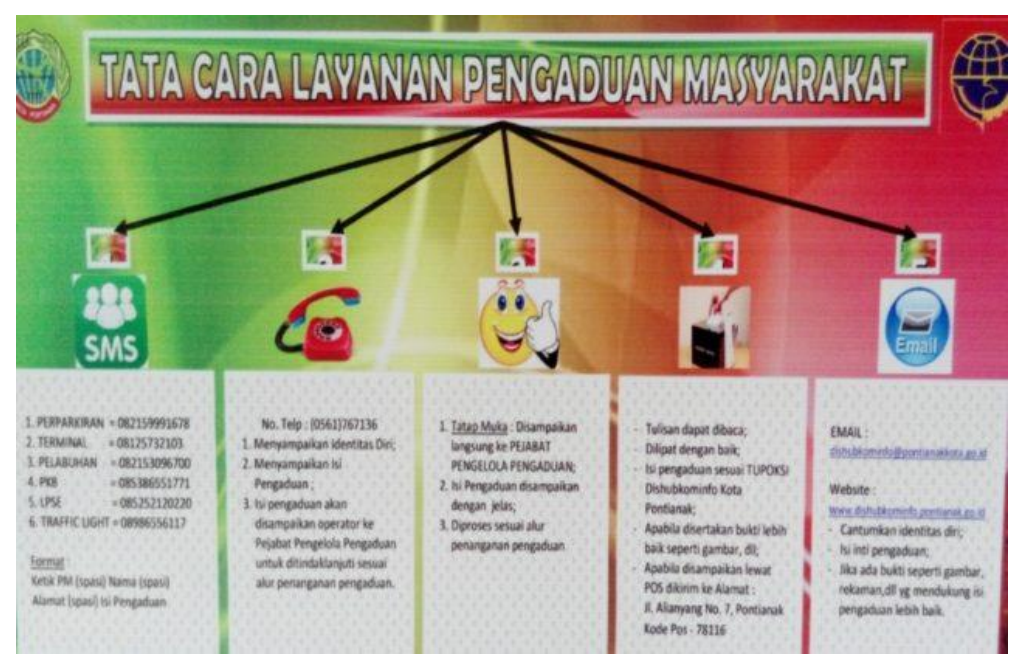

Sumber: Dinas Perhubungan Kota Batam 
Berdasarkan gambar diatas, pengaduan dapat dilakukan melalui sms, telepon, ataupun melalui email yang berkaitan langsung dengan Dinas Perhubungan Kota Batam. Hal ini bagian dari upaya Dinas Perhubungan untuk menampung keluhan masyarakat terkait angkutan umum khususnya angkot.

3. Artikel atau media masa

Artikel dalah karangan faktual secara lengkap dengan panjang tertentu yang dibuat untuk dipublikasikan (melalui koran, majalah, buletin, dsb) dan bertujuan menyampaikan gagasan dan fakta yang dapat meyakinkan, mendidik, dan menghibur.

Gambar 7: Artikel Tentang Kecelakaan Angkutan Kota di Kota Batam

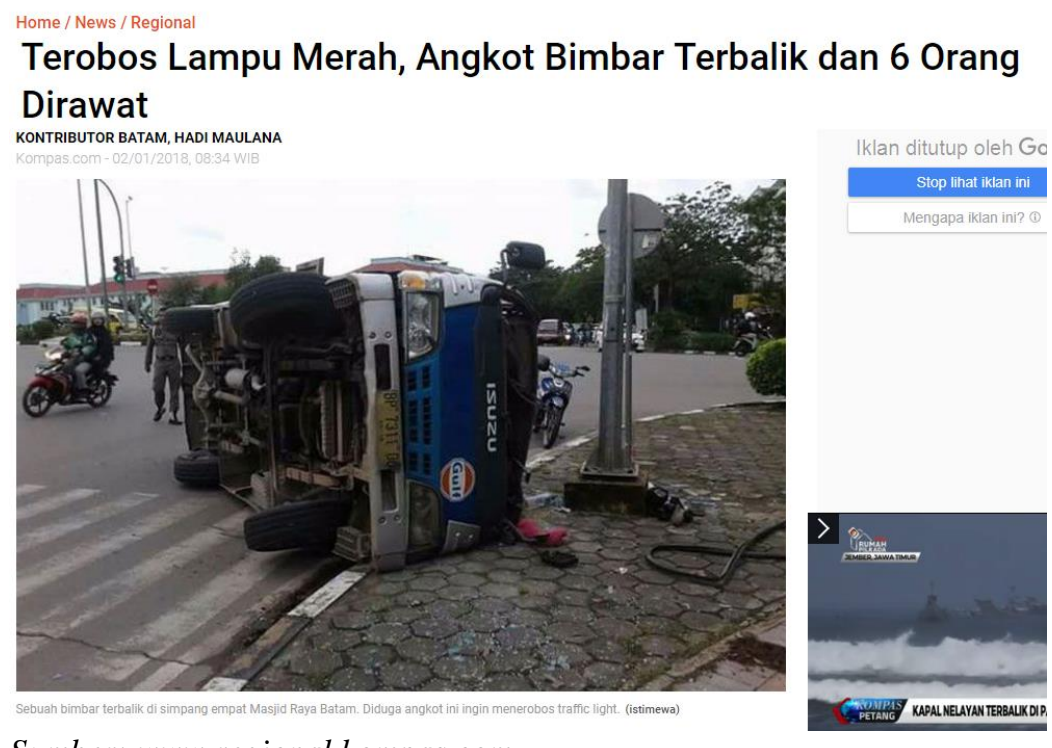

Sumber: www.regional.kompas.com

BATAM, KOMPAS.com - Sebuah angkutan kota Bimbar tujuan Jodoh-Batu Aji-Tanjung Uncang via Batam Center mengalami kecelakaan di simpang empat Masjid Raya Batam Centre atau perempatan lampu lalu lintas Dataran Engku Putri, Selasa (2/2/2108) sekitar pukul 07.12 WIB. Belum diketahui penyebab pastinya, namun informasi di lapangan menyebutkan kecelakaan ini terjadi akibat sopir angkot tersebut mencoba untuk menerobos lampu merah. Namun saat di tingkungan, angkot yang posisinya dalam keadaan kencang kehilangan kendali dan akhirnya terbalik lalu menabrak pembatas jalan. 


\section{KESIMPULAN}

Berdasarkan hasil penelitian dan pembahasan yang dilakukan oleh peneliti mendapatkan berbagai informasi, dimana dari informasi dan data-data tersebut dapat menjadi landasan untuk menilai bagaimana Analisis Fungsi Pengawasan Uji Berkala Oleh Dinas Perhubungan Terhadap Angkutan Kota di Kota Batam menyimpulkan bahwa masih banyaknya angkutan umum yang tidak sesuai dengan standar operasional menunjukkan lemahnya pengawasan dalam penertiban angkutan umum. Peneliti melihat masih banyak terdapat beberapa pelanggaran-pelanggaran dan kurangnya pengawasan penertiban yang dilakukan oleh Dinas Perhubungan. Pengukuran terhadap pengawasan dalam penertiban angkutan umum menggunakan 3 indikator.

Pengawasan uji KIR yang dilakukan terhadap angkutan kota dilakukan secara langsung maupun tidak langsung. pengawasan uji KIR yang dilakukan secara langsung meliputi:

1. Pengujian Berkala Kendaraan Bermotor (PBKB),yang dilakukan oleh Dinas Perhubungan Kota Batam sesuai dengan standar operasional, namun perlu adanya peningkatan pengawasan pada saat pengujian Berkala Kendaraan Bermotor dilakukan agar mencegah terjadinya kecurangan saat pengujian berlangsung.

2. Pemeriksaan dan Ujian Fisik, dalam pelaksanaan di lapangan, masih banyak badan usaha atau supir angkutan yang tidak melakukan uji berkala KIR dengan berbagai alasan, tetapi yang sering ditemukan yaitu banyak usia kendaraan angkutan umum di Kota Batam yang lebih dari 1.5 tahun, hal itu yang membuat para pemilik kendaraan takut untuk melakukan pemeriksaan pengujian berkala kendaraan. Perlu adanya sosialisasi dari pihak Dinas Perhubungan baik kepada badan usaha, supir angkutan maupun penumpang (masyarakat). Agar saling bekerja sama memajukan transportasi di Kota Batam menjadi lebih baik lagi.

3. Pengesahan Hasil Uji, setelah para pemilik kendaraan melakukan pengujian maka akan diberikan tanda telah melaksanakan pengujian tersebut, seperti diberikan buku uji, plat uji dan tanda samping (stiker) yang ditempelkan pada badan mobil. Dalam pelaksanaannya, masih ditemukan kecurangan yang terjadi, seperti pemalsuan buku KIR yang dilakukan oleh oknum-oknum yang tidak bertanggung jawab. Hal ini 
perlu menjadi pembelajaran bagi pihak pemerintah khususnya Dinas Perhubungan dalam mengatasi permasalahan ini.

Sedangkan pengawasan uji KIR yang dilakukan secara tidak langsung dilihat melalui:

1. Dokumen

Mengenai uji KIR yang dilakukan Dinas Perhubungan kepada badan usaha angkutan kota yang ada di Kota Batam, bahwa masih banyak angkutan kota yang sudah tidak laik beroperasi dikarenakan usia kendaraan yang melebihi batas ketentuan yaitu 15 tahun.

2. Pengaduan

Banyaknya keluhan atau pengaduan masyarakat atau penumpang terkait rasa tidak nyaman yang dirasakan saat menaiki angkot, dikarenakan keadaan angkot banyak yang rusak. Dan supir angkot yang ugal-ugalan.

3. Berita atau artikel di media masa

Kecelakaan yang terjadi di Kota Batam disebabkan oleh beberapa faktor dan dari berbagai jenis kendaraan. tidak dapat di pungkiri angkutan kota termasuk jenis angkutan tersebut. hal itu pun dapat dilihat dari postingan berita terkait angkutan kota yang kecelakaan disebabkan rem blong, ataupun angkot yang melebihi kapasitas. Dan banyak juga terjadi kecelakaan dikarenakan supir angkutan yang tidak hati-hati saat berkendara.

\section{Saran}

Untuk melihat hasil dari pengawasan Dinas Perhubungan Kota Batam dalam menangani penertiban angkutan umum, melalui skripsi ini peneliti menyarankan hal-hal sebagai berikut:

1. Dalam hal menangani penertiban angkutan umum, disarankan agar Dinas Perhubungan bertindak lebih tegas lagi sesuai dengan prosedur yang berlaku dalam menangani supir angkutan yang tidak mematuhi aturan yang berlaku, dengan lebih mengedepankan sikap ramah, bijaksana agar tidak terjadi kesalahpahaman antara pegawai Dinas Perhubungan dengan supir angkutan umum. 
2. Perlu adanya sosialisasi baik kepada badan usaha maupun penumpang agar adanya kerja sama dalam mewujudkan transportasi yang lebih baik kedepannya di Kota Batam.

3. Bentuk perlindungan hukum masalah kenyamanan bukan hanya bertumpu pada pemilik bus maupun supir, seharusnya Dinas Perhubungan juga memperhatikan kenyamanan dan keamanan penumpang dengan mentidakloloskan uji kelayakan kepada bus yang seharusnya memang tidak laik jalan.

4. Diharapkan kepada Dinas Perhubungan seharusnya ada layanan baik melalui kotak saran yang ada pada setiap halte ataupun layanan pengaduan online yang memudahkan masyarakat (penumpang) yang merasa tidak nyaman saat menaiki transportasi. dengan begitu, ada evaluasi bagi pihak Dinas Perhubungan dalam memperbaiki sistem transportasi khususnya angkutan umum yang sering di jumpai di jalanan Kota Batam.

\section{REFERENSI}

Sofyan,Safri. 2004. Sistem Pengawasan Manajemen, Jakarta: PT Pustaka Quantum.

Raharjo, Adisasmita. 2011. Manajemen Pemerintahan Daerah, Yogyakarta: Graha Ilmu.

Kartono, 2002. Persamaan Diferensial Biasa Model Matematika Fenomena Perubahan.Yogyakarta: Graha Ilmu.

Sule, Trisnawati Ernie dan Saefullah, Kurniawan, 2005. Pengantar Manajemen.Kencana: Jakarta.

Sudarsono dan Edilius, 2002. Manajemen Koperasi Indonesia. Jakarta: Rineka Cipta.

Victor, M. Situmorang, dan Jusuf Juhir, 2001. Aspek Hukum Pengawasan Melekat.Yogyakarta: Rineka Cipta.

Ukas, maman, 2004. Manajemen Konsep, Prinsip Dan Aplikasi. Cetakan ketiga. Bandung: Agnini.

Siagian, Sondang, 2007. Fungsi-fungsi manajerial. Bumi aksara. Jakarta.

Erni,Daly. 2008. Kajian Implementasi Peraturan Perundang-undangan. Jakarta: Kencana Fattah. 
Satori, Djam'an \& Aan Komariah, 2009. Metode Penelitian Kualitatif. Bandung :Alfabeta.

Fattah Nanang, 2004. Prinsip-prinsip Manajemen. Bina Aksara. Jakarta.

Nur, Nasution, 2003. Manajemen Transportasi. Ghalia Indonesia. Indonesia

Soesilo, Nining I, 1999. Ekonomi Perencanaan dan Manajemen Kota. Jakarta.

Tamin, Ofyar Z, 1997. Perencanaan dan Pemodelan Transportasi. Bandung: ITB.

Usman, Husaini \& Purnomo Setiady Akbar, 2006. Pengantar Statistik. Jakarta: Bumi aksara.

Victor, M. Situmorang, dan Jusuf Juhir, 2001. Aspek Hukum Pengawasan Melekat.Yogyakarta: Rineka Cipta.

Undang-Undang Nomor. 22 Tahun 2009 Tentang Lalu Lintas dan Angkutan Jalan

Undang-Undang Nomor 22 Tahun 2009 Pasal 4

Peraturan Walikota Batam Nomor 30 Tahun 2013 tentang Pembentukan Unit Pelaksana

Teknis Pelayanan Jasa Transportasi Pada Dinas Perhubungan Kota Batam

Sejarah Kota Batam, Pemko 2017

www.dishub.batam.go.id

www.situs Pemerintahan Kota Batam-Wikipedia-Hatanto Reksodipoetro Pimpinan BP

Batam-bahasa-Indonesia

http://petabatam.com/sejarah-2/kota-Batam.html

Batam.go.id/profil-geografis.html

www.jotravelguide.com/transportasi_di_Batam.php 